\title{
Dissecting the roles of thymoquinone on the prevention and the treatment of hepatocellular carcinoma: an overview on the current state of knowledge
}

\author{
Sabrina Bimonte ${ }^{1 *+} \mathbb{D}$, Vittorio Albino ${ }^{2 \dagger}$, Antonio Barbieri $^{3 \dagger}$, Maria Luisa Tamma ${ }^{1}$, Aurelio Nasto ${ }^{4}$, Raffaele Palaia ${ }^{2}$, \\ Carlo Molino ${ }^{5}$, Paolo Bianco ${ }^{6}$, Andrea Vitale $^{6}$, Rita Schiano ${ }^{6}$, Aldo Giudice $^{7}$ and Marco Cascella ${ }^{1+}$
}

\begin{abstract}
Thymoquinone (TQ) is the principal active monomer isolated from the seed of the medicinal plant Nigella sativa. This compound has antitumor effects against various types of cancer including hepatocellular carcinoma (HCC), mainly due to its anti-inflammatory and anti-oxidant properties. Several pre-clinical studies showed that TQ, through the modulation of different molecular pathways, is able to induce anti-apoptotic and anti-proliferative effects in HCC, without signs of toxicity. Moreover, it has been suggested that TQ has hepatoprotective effects by enhancing the tolerability and effectivity of neoadjuvant therapy prior to liver surgery, although the underlying mechanisms are not completely understood. Based on these findings, is assumable that TQ could represent a valuable therapeutic option for patients suffering from HCC. In this review, we summarize the potential roles of TQ in the prevention and treatment of HCC, by revising the preclinical studies and by highlighting the potential applications of TQ as a therapeutic choice for HCC treatment into clinical practices.
\end{abstract}

Keywords: Nigella sativa, Thymoquinone, Hepatocellular carcinoma, Cell proliferation, Cell apoptosis

\section{Background}

Thymoquinone (TQ) is the predominant bioactive constituent present in the volatile oil of black seed (Nigella sativa), particularly used as a condiment in the Middle East [1-4]. Accumulating of evidence showed that TQ has anti-oxidant effects and anti-proliferative effects in many types of cancer, including liver tumors, without signs of toxicity to normal cells [5-11]. Moreover, it has been proved that TQ and Nigella sativa possess hepatoprotective effects by enhancing the tolerability and the effectivity of neoadjuvant therapy prior to liver surgery [12-16]. As regards to hepatocellular carcinoma (HCC), due to the unavailability of successful therapy for HCC patients mainly for those at an advanced stage

\footnotetext{
* Correspondence: s.bimonte@istitutotumori.na.it

Sabrina Bimonte, Vittorio Albino, Antonio Barbieri and Marco Cascella are cofirst authors.

'Division of Anesthesia and Pain Medicine, Istituto Nazionale Tumori, IRCCS -

Fondazione G Pascale, Naples, Italy, Naples, Italy

Full list of author information is available at the end of the article
}

of disease [17-20], new alternative therapies based on the use of natural compounds as a supplement to conventional schedules for HCC treatment, should be taken into account [21]. Based on these findings, is assumable that TQ could be considered a therapeutic option for the prevention and the treatment of HCC. For this purpose, we summarize the potential roles of TQ in the prevention and treatment of HCC, by revising the preclinical studies and by highlighting the potential applications of TQ as a therapeutic choice for HCC treatment into clinical practices.

TQ: chemical structure, biological properties, and roles in the human hepatocellular carcinoma

Thymoquinone (TQ) or 2-isopropyl-5-methyl-1, 4benzoquinone (Fig. 1), is the predominant constituent derived from the seeds of Nigella sativa whose composition has been previously described by Mollazadeh et al [14]. Many in vivo and in vitro reports have demonstrated the therapeutic efficacy of TQ against a wide

(c) The Author(s). 2019 Open Access This article is distributed under the terms of the Creative Commons Attribution 4.0 International License (http://creativecommons.org/licenses/by/4.0/), which permits unrestricted use, distribution, and 
NF-кB, GSHPx $\uparrow$, CAT $\uparrow$ GST $\uparrow$

Ki67 $\downarrow$, CD4K $\downarrow$, Cyclin D1 $\downarrow$, CDK4 $\downarrow$,

p21 ${ }^{\mathrm{WAF} 1 / \mathrm{CIP} 1} \uparrow$, PCNA $\downarrow$

$\mathrm{NF}-\kappa B \downarrow I L-8 \downarrow, \operatorname{ROS} \uparrow$ NQO1 $\uparrow$ HO-1 $\uparrow$,

NICD1 $\downarrow$, Bcl-2 $\downarrow$, Notch1 $\downarrow$, p21 $\uparrow$ Bcl-xS $\uparrow$

TRAIL death receptors $\uparrow ;$ Bcl-2 $\downarrow$

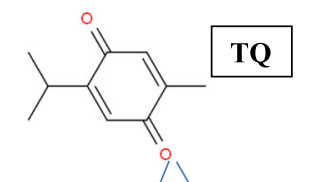

TQ

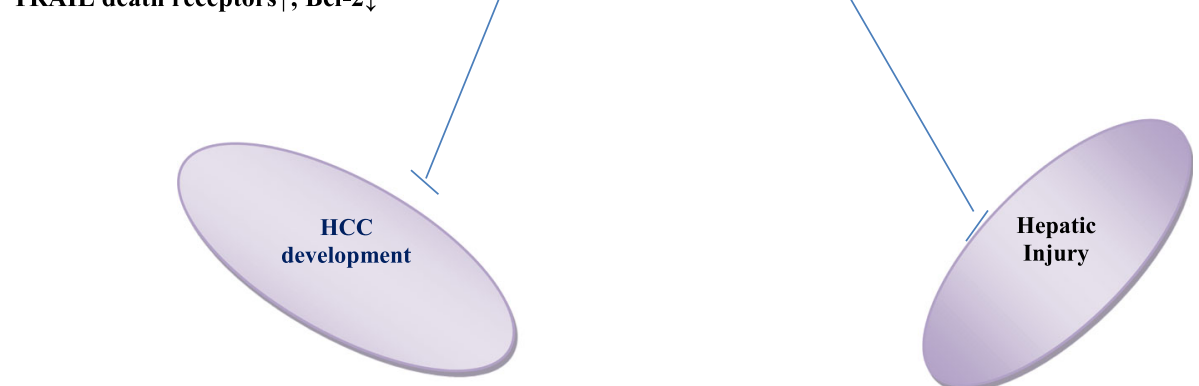

Fig. 1 Key signaling pathways that regulate the function of TQ in HCC develepoment and in the hepatic injury. The cartoon recapitulates the principle signaling pathways by which TQ blocks hepatocellular carcinoma growth (a) and the hepatic injury (b). Abbreviations: GSHPx: glutathione peroxidase; CAT: catalase; GST: glutathione-s-transferase; Ki67: cell proliferating markers(Labeling index); PCNA: proliferating cellular antigen; CDK4: Cyclin-Dependent Kinase 4; NF-KB: Nuclear factor kappa-light-chain-enhancer of activated B cells; ROS: reactive oxygen species; NQO1: NADFH quinone oxidoreductase 1; HO-1: Heme oxygenase isoenzime-1; TRAIL: Tumor necrosis factor-related apoptosis-inducing ligand; BCl-2: BCL2, Apoptosis Regulator; Notch1: Neurogenic locus notch homolog protein 1; NICD1: notch intracellular domain 1; BAX: Bcl-2 Associated $X$, Apoptosis Regulator

range of cancer including ovarian cancer, breast cancer [22], pancreatic cancer [23], lung cancer [24], fibrosarcoma [25], neuroblastoma [26], osteosarcoma [27] and myeloma [28]. Due to its chemical structure, TQ is able to act as a free radical and as a superoxide radical scavenger [29]. TQ exerts its anti-inflammatory and immunomodulatory effects by acting on specific signaling pathways as nuclear factor kappa-light-chain-enhancer of activated B cells (NF-kB), interleukin 1- beta (IL-1 $\beta$ ), TNF- $\alpha$ (Tumor necrosis factor-alfa) [30]. Regarding HCC, it has been reported that TQ is able to inhibit tumor growth by regulating the cell cycle progression and the apoptosis, through the repression of the Notch signaling pathway [31]. In addition, TQ and Nigella sativa have a chemopreventive role in $\mathrm{HCC}$ by inhibiting the EGFR/ERK1/2 signaling pathway (Fig. 1) [15].

\section{Pre-clinical shreds of evidence on the role of TQ in HCC cell growth: a current state of the art}

Accumulating pieces of pre-clinical evidence shed a light on the inhibitory role of TQ in HCC initiation and progression. The first study has been conducted on rats with hepatocarcinogenesis-induced by diethylnitrosamine (DENA, $200 \mathrm{mg} / \mathrm{kg}$, I.P.) [32]. The authors showed that TQ $(4 \mathrm{mg} / \mathrm{kg} /$ day delivered in drinking water) was able to counteract the DENA-induced initiation of liver cancer. Particularly, TQ restored the biochemical values and the histopathological damages in liver tissues induced by DENA. Moreover, due to its anti-oxidant properties, TQ preserved the activity and mRNA expression of antioxidant enzymes as nitrate/ nitrite (NOx), glutathione (GSH), glutathione peroxidase (GSHPx), glutathione-s-transferase (GST) and catalase (CAT) which were altered by DENA (Table 1). Subsequently, in a fascinating study, et al. [33], showed that TQ $(20 \mathrm{mg} / \mathrm{kg})$ had anti-proliferative effects in experimental rats with hepatocarcinogenesis induced by $\mathrm{N}$-nistrodiethhylamine (NDEA, 0,01\% in drinking water), by arresting the cycle progression at G1/S phase. Specifically, TQ reduced the levels of liver injury and tumor markers and restored the normal parenchymal liver architecture which was altered by NDEA-administration. Finally, the anti-proliferative effect of TQ was assessed firstly, by evaluating the expression profile of cell proliferating markers, Ki67 and proliferating cellular antigen (PCNA), secondly, by analyzing the TQ's action on the regulation of cell cycle progression on G1/S phase. This latter aim was 
Table 1 A summary of pre-clinical studies on the role of TQ in hepatocellular carcinoma cell growth

\begin{tabular}{|c|c|c|c|c|}
\hline Cell lines & Animal model & Dose of TQ & Molecular targets & Reference \\
\hline & $\begin{array}{l}\text { Rats with Hepatocarcinogenesis- } \\
\text { induced by diethylnitrosamine } \\
\text { (DENA } 200 \text { mg/kg, I.P.). }\end{array}$ & $\begin{array}{l}50 \mathrm{mg} / \mathrm{L} \text { in drinking water }=4 \mathrm{mg} / \mathrm{kg} \\
\text { daily for } 7 \text { consecutive days. }\end{array}$ & 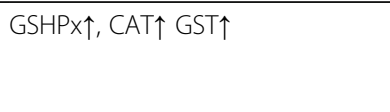 & [32] \\
\hline & $\begin{array}{l}\text { Rats with hepatocarcinogenesis } \\
\text { induced by N-nistrodiethhylamine } \\
\text { (NDEA, 0,01\% in drinking water) }\end{array}$ & $\begin{array}{l}20 \mathrm{mg} / \mathrm{kg} \text { body weight daily from } \\
\text { the } 3 \text { th to } 5 \text { th week of treatments. } \\
\text { (oral gavage) }\end{array}$ & $\begin{array}{l}\text { Ki67 } \downarrow \text {, PCNA, Cyclin D1 } \downarrow \text {, CDK4 } \downarrow \\
\text { and } 221^{\text {WAF } 1 / C 1 P 1} \uparrow,\end{array}$ & [33] \\
\hline HepG2 & & $12.5,25$ or $50 \mathrm{M} \mathrm{\mu M}$ for $24 \mathrm{~h}$ & $\begin{array}{l}\mathrm{NF}-\mathrm{KB} \downarrow \text {, IL-8 } \downarrow \text {, ROS } \uparrow \text { NQO } 1 \uparrow \mathrm{HO}- \\
1 \uparrow, \mathrm{BCl}-\mathrm{xS} \uparrow, \text { TRAIL death recep- } \\
\text { tors } \uparrow ; \mathrm{BCl}-2 \downarrow\end{array}$ & [34] \\
\hline \multirow[t]{2}{*}{$\begin{array}{l}\text { Hep3B, SMMC7721, HepG2, } \\
\text { Bel7402, MHCC97-L, } \\
\text { MHCC97-H, HHCC }\end{array}$} & & $20,40,60,80 \mu \mathrm{M}$ from 24 to $72 \mathrm{~h}$. & $\begin{array}{l}\text { BCl-2 } \downarrow, \text { Notch } 1 \downarrow, \text { NICD } 1 \downarrow, \\
\text { Jagged1 } 1, \text { Hes } 1 \downarrow \text { cyclin D1 } 1, \\
\text { CDK2 } 2 \text { p } 21 \uparrow, \text { Bax } \uparrow\end{array}$ & [31] \\
\hline & $\begin{array}{l}\text { Liver tumor xenografts in athymic } \\
\text { nude mice (Hep cells) }\end{array}$ & $\begin{array}{l}5 \mathrm{mg} / \mathrm{kg} \text { daily (subcutaneously } \\
\text { injected); } 20 \mathrm{mg} / \mathrm{kg} \text { daily } \\
\text { (subcutaneously injected) for } \\
31 \text { days. }\end{array}$ & 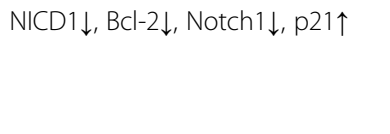 & [31] \\
\hline
\end{tabular}

Abbreviations: GSHPx glutathione peroxidase, CAT catalase, GST glutathione-s-transferase, Ki67 cell proliferating markers(Labeling index), PCNA proliferating cellular antigen, CDK4 Cyclin-Dependent Kinase 4, NF-KB nuclear factor kappa-light-chain-enhancer of activated B cells, ROS reactive oxygen species, NQO1 NADFH quinone oxidoreductase 1, HO-1 Heme oxygenase isoenzime-1, TRAIL tumor necrosis factor-related apoptosis-inducing ligand, BCl-2 BCL2, Apoptosis Regulator, Notch1 neurogenic locus notch homolog protein 1, NICD1 notch intracellular domain 1, Jagged1 protein jagged-1, Hes1 Hes Family BHLH Transcription Factor, CDK2 Cycle

achieved by evaluating the expression of typical cell cycle proteins, CD4K, Cyclin D1, CDK4, and p $21^{\mathrm{WAF} 1 / \mathrm{CIP} 1}$, by the experiment of immunoprecipitation on rats of each group of treatment (Table 1). Results from these studies suggested that TQ was able to suppress hepatocellular tumor growth by inhibiting the proliferation and by arresting the cell cycle progression on the G1/S phase.

Similar findings were reported by Ashour et al in vitro experiments on HepG2 cells [34]. Specifically, TQ was able to inhibit the growth of HCC cells by arresting cell cycle on G2M phase and by activating the expression of caspase- 3 and caspase- 9 and the cleavage of poly (ADP-ribose) polymerase. Moreover, TQ was able to enhance the TRAIL-induced death of HepG2 cells, thought the up-regulation of death receptors, the inhibition of Nuclear factor kappa-B (NF-kB) and interleukin-8 (IL-8), the stimulation of reactive oxygen species (ROS) and mRNAs of $\mathrm{NAD}(\mathrm{P}) \mathrm{H}$ quinone dehydrogenase 1 (NQO1) and heme oxygenase 1 (HO-1). These results suggest that TQ could be considered a potential substance for the prevention and the treatment of HCC. In a fascinating in vitro and in vivo studies, a pivotal role of TQ in the inhibition of HCC cell growth was also reported [31]. Basically, the authors showed a retarded tumor cell growth induced by TQ treatment accompanied by arresting the cell cycle in G1 phase (SMMC7721 cells) or in $\mathrm{S}$ phase (Hep3B cells) and by upregulating p21 and downregulating CDK2 and cyclinD1 expression according to TQ concentrations. Moreover, TQ enhanced apoptosis by decreasing $\mathrm{Bcl}-2$ expression and increasing Bax expression. These findings were confirmed in a xenograft mouse model of HCC. Particularly, tumors of xenograft liver mice showed a decreased expression of NICD1 and Bcl-2 levels while an increment of p21 expression was observed. Altogether, these data suggest that TQ inhibits HCC growth by inhibiting the Notch signaling pathway.

\section{Mechanism of action: a link between the hepatoprotective effects of TQ and its antioxidant properties}

Despite the inhibitory role of TQ on HCC cell growth, several in vivo reports on different liver models [13, 3553], shed a light on the hepatoprotective effects of TQ, commonly associated to its antioxidant properties. In a fascinating systematic review, Tekbas et al. [13] suggested that TQ, due to its multiple properties, could be considered as a new substance that reduced the hepatic injury.

It is well assumed, that liver injury is commonly associated with changes in the expression of the principal liver enzymes and in liver tissue damage which is commonly attributed to an oxidative stress [13]. Results from the above-mentioned studies on different liver models suggest that TQ has a hepatoprotective role by increasing the resistance to oxidative stress, through the regulation of the oxidative markers content.

Specifically, TQ is able to prevent malondialdehyde (MDA) production [37-45], to block the lipid peroxidation $[38,46-49]$, to reduce the content of nitric oxide (NO) $[50,52]$ and to decrease the concentration of GSH $[39,43,44,49-51,53]$. The underlying mechanism is mainly based on the inhibition of oxygen free radicals production induced by $\mathrm{TQ}$, which in turn regulates the inflammatory molecular pathways as NF-kB, tumor 
necrosis factor (TNF- $\alpha$ ), interleukin (IL-1 $\beta$ ) and the nitric oxide signaling pathway.

An interesting study on the protective mechanism of TQ on HCC was recently demonstrated in rats with HCC induced by diethylnitrosamine (DENA) [32]. The authors identified the EGFR/ERK1/2 signaling pathway as the underlying mechanism by which TQ exerted the hepatoprotective function. Moreover, TQ was able to protect liver thanks to its antioxidant properties by enhancing the activity of superoxide dismutase (SOD), glutathione peroxidase (GPx), catalase (CAT) and glutathione- s-transferase (GST).

Taken together, these findings, suggest that TQ could be considered not only a potential drug for the prevention and the treatment of HCC but also as a hepatoprotective agent in HCC patients.

\section{Conclusions}

Several pre-clinical studies depicted here demonstrated that TQ induces apoptosis and restrains HCC progression by acting on different molecular pathways. These findings largely support the use of TQ into clinical practice for HCC counteraction and treatment. Despite TQ compound is currently used in clinical trials for the treatment of different type of cancer and other diseases, no clinical trials have been performed, until now, for patients suffering from HCC. For these reasons, more studies are extremely needed. These examinations ought to be engaged 1) on the understanding of the molecular mechanism regulated by TQ in HCC; 2) on the identification of the optimum therapeutic dosage of TQ for intervention trials in HCC patients.

\footnotetext{
Abbreviations

ADP: Poly-ribose polymerase; BAX: BCl-2 Associated X, Apoptosis Regulator; BCl-2: BCL2, Apoptosis Regulator; BCl-xS: B-cell lymphoma-extra small; BHLH: Transcription Factor; CAT: Catalase; CDK2: Cyclin-Dependent Kinase 2; CDK4: Cyclin-Dependent Kinase 4; DENA: Diethylnitrosamine;

EGFR: Epidermal growth factor receptor; ERK-1: Extracellular signal-regulated kinase 1; ERK-2: Extracellular signal-regulated kinase 2; GPX: Glutathione peroxidase; GSH: Glutathione; GST: Glutathione-s-transferase;

HCC: Hepatocellular carcinoma; Hes1: Hes Family; Hes1: Hes Family BHLH Transcription Factor; HO-1: Heme oxygenase isoenzime-1; IL-1 $\beta$ : Interleukin 1beta; IL-8: Interleukin-8; Jagged1: Protein jagged-1; Ki67: Cell proliferating markers(Labelling index); MDA: Malondialdehyde; NDEA: Nnistrodiethhylamine; NF-KB: Nuclear factor kappa-light-chain-enhancer of activated B cells; NICD1: Notch intracellular domain 1; NICD1: the released notch intracellular domain 1; Notch1: Neurogenic locus notch homolog protein 1; NOx: Nitrous Oxides; NQO1: NADFH quinone oxidoreductase 1; PCNA: Proliferating cellular antigen; ROS: Reactive oxygen species; SOD: Superoxide-dismutase; TNF-a: Tumour necrosis factor-alfa; TQ: Thymoquinone; TRAIL: Tumour necrosis factor-related apoptosis-inducing ligand
}

\section{Acknowledgements}

The authors are grateful to Alessandra Trocino and Mrs. Maria Cristina Romano from the National Cancer Institute of Naples for providing excellent bibliographic service and assistance.

\section{Availability of data and materials}

Data sharing not applicable to this article as no datasets were generated or analyzed during the current study.

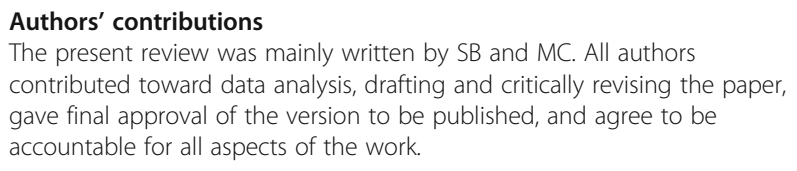

Ethics approval and consent to participate

Not applicable.

\section{Consent for publication}

Not applicable.

\section{Competing interests}

The authors declare that they have no competing interests.

\section{Publisher's Note}

Springer Nature remains neutral with regard to jurisdictional claims in published maps and institutional affiliations.

\section{Author details}

'Division of Anesthesia and Pain Medicine, Istituto Nazionale Tumori, IRCCS Fondazione G Pascale, Naples, Italy, Naples, Italy. ${ }^{2}$ Division of Abdominal Surgical Oncology, Hepatobiliary Unit, Istituto Nazionale Tumori, IRCCS Fondazione G Pascale, Naples, Italy, Naples, Italy. ${ }^{3}$ S.S.D. Sperimentazione Animale, Istituto Nazionale Tumori, IRCCS Fondazione G. Pascale, Naples, Italy. ${ }^{4}$ U. O. C. di Chirurgia Generale ad indirizzo Oncologico P.O. "A. Tortora", Pagani, Salerno, Italy. ${ }^{5}$ Chirurgia Generale AORN A, Cardarelli, Naples, Italy. ${ }^{6}$ Pineta Grande Hospital, Caserta, Italy. ${ }^{7}$ Epidemiology Unit, IRCCS Istituto Nazionale Tumori "Fondazione G. Pascale", 80131 Naples, Italy.

Received: 7 December 2018 Accepted: 8 April 2019

Published online: 16 April 2019

\section{References}

1. Padhye S, Banerjee S, Ahmad A, Mohammad R, Sarkar FH. From here to eternity-the secret of pharaohs: therapeutic potential of black cumin seeds and beyond. Cancer Ther. 2008;6:495-510.

2. Ali BH, Blunden G. Pharmacological and toxicological properties of Nigella sativa. Phytother Res. 2003;17:299-305.

3. Cascella M, Bimonte S, Barbieri A, et al. Dissecting the potential roles of Nigella sativa and its constituent Thymoquinone on the prevention and on the progression of Alzheimer's disease. Front Aging Neurosci. 2018;10:16.

4. Cascella M, Palma G, Barbieri A, et al. Role of Nigella sativa and its constituent Thymoquinone on chemotherapy-induced nephrotoxicity: evidences from experimental animal studies. Nutrients. 2017;9(6):625.

5. Woo CC, Hsu A, Kumar AP, Sethi G, Tan KH. Thymoquinone inhibits tumor growth and induces apoptosis in a breast cancer xenograft mouse model: the role of p3 MAPK and ROS. PLoS One. 2013;8:e75356.

6. Kaseb AO, Chinnakannu K, Chen D, Sivanandam A, Tejwani S, Menon M, Dou QP, Reddy GP. Androgen receptor and E2F-1-targeted Thymoquinone therapy for hormone-refractory prostate Cancer. Cancer Res. 2007;67:7782-8.

7. Banerjee S, Kaseb AO, Wang Z, Kong D, Mohammad M, Padhye S, Sarkar FH, Mohammad RM. Antitumor activity of gemcitabine and oxaliplatin is augmented by thymoquinone in pancreatic cancer. Cancer Res. 2009; 69:5575-83.

8. Li F, Rajendran P, Sethi G. Thymoquinone inhibits proliferation, induces apoptosis and chemosensitizes human multiple myeloma cells through suppression of signal transducer and activator of transcription 3 activation pathway. Br J Pharmacol. 2010;161:541-54.

9. Woo CC, Kumar AP, Sethi G, Tan KH. Thymoquinone: potential cure for inflammatory disorders and cancer. Biochem Pharmacol. 2012;83:443-51.

10. Jafri SH, Glass J, Shi R, Zhang S, Prince M, Kleiner-Hancock H. Thymoquinone and cisplatin as a therapeutic combination in lung cancer: In vitro and in vivo. J Exp Clin Cancer Res. 2010;29(1):87.

11. Ashour AE, Abd-Allah AR, Korashy HM, Attia SM, Alzahrani AZ, Saquib Q, Bakheet SA, Abdel-Hamied HE, Jamal S, Rishi AK. Thymoquinone suppression of the human hepatocellular carcinoma cell growth involves 
inhibition of IL-8 expression, elevated levels of TRAIL receptors, oxidative stress and apoptosis. Mol Cell Biochem. 2014;389:85-98.

12. Tabassum H, Ahmad A, Ahmad IZ. Nigella sativa L. and its bioactive constituents as Hepatoprotectant: a review. Curr Pharm Biotechnol. 2018;19:43.

13. Tekbas A, Huebner J, Settmacher U, Dahmen U. Plants and surgery: the protective effects of Thymoquinone on hepatic injury-a systematic review of in vivo studies. Int J Mol Sci. 2018;19(4):1085.

14. Mollazadeh $\mathrm{H}$, Afshari AR, Hosseinzadeh $\mathrm{H}$. Review on the potential therapeutic roles of Nigella sativa in the treatment of patients with Cancer: involvement of apoptosis: - Black cumin and cancer. J Pharmacopuncture. 2017;20(3):158-72.

15. Shahin YR, Elguindy NM, Abdel Bary A, Balbaa M. The protective mechanism of Nigella sativa against diethylnitrosamine-induced hepatocellular carcinoma through its antioxidant effect and EGFR/ERK1/2 signaling. Environ Toxicol. 2018:33:885-98.

16. Abd-Elbaset M, Arafa ESA, El Sherbiny GA, Elgendy AN. Thymoquinone mitigate ischemia-reperfusion-induced liver injury in rats: a pivotal role of nitric oxide signaling pathway. Naunyn Schmiedebergs Arch Pharmacol. 2017;390:69.

17. Forner A, Llovet JM, Bruix J. Hepatocellular carcinoma. Lancet. 2012;379:1245-55.

18. Peng ZW, Zhang YJ, Chen MS, Xu L, Liang HH, Lin XJ, Guo RP, Zhang YQ, Lau WY. Radiofrequency ablation with or without transcatheter arterial chemoembolization in the treatment of hepatocellular carcinoma: a prospective randomized trial. J Clin Oncol. 2013;31:426-32.

19. Llovet JM, Ricci S, Mazzaferro V, Hilgard P, Gane E, Blanc JF, de Oliveira AC, Santoro A, Raoul JL, Forner A, Schwartz M, Porta C, Zeuzem S, et al. Sorafenib in advanced hepatocellular carcinoma. N Engl J Med. 2008;359:378-90.

20. Zhu AX, Rosmorduc O, Evans TR, Ross PJ, Santoro A, Carrilho FJ, Bruix J, Qin S, Thuluvath PJ, Llovet JM, Leberre MA, Jensen M, Meinhardt G, et al. SEARCH: a phase III, randomized, double-blind, placebo-controlled trial of Sorafenib plus Erlotinib in patients with advanced hepatocellular carcinoma. J Clin Oncol. 2015;33:559-66.

21. Moreno FS, Heidor R, Pogribny IP. Nutritional epigenetics and the prevention of hepatocellular carcinoma with bioactive food constituents. Nutr Cancer. 2016 Jul;68(5):719-33.

22. Shoieb AM, Elgayyar M, Dudrick PS, Bell JL, Tithof PK. In vitro inhibition of growth and induction of apoptosis in cancer cell lines by thymoquinone. Int J Oncol. 2003:22:107-13.

23. Relles D, Chipitsyna Gl, Gong Q, Yeo CJ, Arafat HA. Thymoquinone promotes pancreatic Cancer cell death and reduction of tumor size through combined inhibition of histone Deacetylation and induction of histone acetylation. Adv Prev Med. 2016;2016:1407840.

24. Samarghandian S, Azimi-Nezhad M, Farkhondeh T. Thymoquinone-induced antitumor and apoptosis in human lung adenocarcinoma cells. J Cell Physiol. 2018:1-11.

25. Badary OA, Gamal El-Din AM. Inhibitory effects of thymoquinone against 20methylcholanthrene-induced fibrosarcomatumorigenesis. Cancer Detect Prev. 2001;25(4):362-8.

26. Arumugam P, Subramanian R, Priyadharsini JV, Gopalswamy J. Thymoquinone inhibits the migration of mouse neuroblastoma (Neuro-2a) cells by downregulating MMP-2 and MMP-9. Chin J Nat Med. 2016;14(12):904-12.

27. Peng L, Liu A, Shen $Y, X u$ H, Yang S, Ying X, Shen W. Antitumor and antiangiogenesis effects of thymoquinone on osteosarcoma through the NF-kB pathway. Oncol Rep. 2013;29:571-8.

28. Siveen KS, Mustafa N, Li F, et al. Thymoquinone overcomes chemoresistance and enhances the anticancer effects of bortezomib through abrogation of $\mathrm{NF}-\mathrm{KB}$ regulated gene products in multiple myeloma xenograft mouse model. Oncotarget. 2013;5(3):634-48.

29. Badary OA, Taha RA, Gamal El-Din AM, Abdel-Wahab MH. Thymoquinone is a potent superoxide anion scavenger. Drug Chem Toxicol. 2003;26(2):87-98.

30. Khan MA, Younus $\mathrm{H}$. Thymoquinone shows the diverse therapeutic actions by modulating multiple cell signaling pathways: single drug for multiple targets. Curr Pharm Biotechnol. 2018;19(12):934-45.

31. Ke X, Zhao Y, Lu X, et al. TQ inhibits hepatocellular carcinoma growth in vitro and in vivo via repression of notch signaling. Oncotarget. 2015;6(32): 32610-21.

32. Sayed-Ahmed MM, Aleisa AM, Al-Rejaie SS, et al. Thymoquinone attenuates diethylnitrosamine induction of hepatic carcinogenesis through antioxidant signaling. Oxidative Med Cell Longev. 2010;3(4):254-61.

33. Raghunandhakumar S, Paramasivam A, Senthilraja S, Naveenkumar C, Asokkumar S, Binuclara J, Jagan S, Anandakumar P, Devaki T.
Thymoquinone inhibits cell proliferation through regulation of G1/S phase cell cycle transition in $\mathrm{N}$-nitrosodiethylamine-induced experimental rat hepatocellular carcinoma. Toxicol Lett. 2013;223(1): 60-72.

34. Ashour AE, Abd-Allah AR, Korashy HM, Attia SM, Alzahrani AZ, Saquib Q, Bakheet SA, Abdel-Hamied HE, Jamal S, Rishi AK. Thymoquinone suppression of the human hepatocellular carcinoma cell growth involves inhibition of IL-8 expression, elevated levels of TRAIL receptors, oxidative stress and apoptosis. Mol Cell Biochem. 2014;389(1-2):85-98.

35. Mansour MA, Ginawi OT, El-Hadiyah T, El-Khatib AS, Al-Shabanah OA, AlSawaf HA. Effects of volatile oil constituents of Nigella sativa on carbon tetrachloride-induced hepatotoxicity in mice: evidence for antioxidant effects of thymoquinone. Res Commun Mol Pathol Pharmacol. 2001;110; 239-51.

36. Mansour MA. Protective effects of thymoquinone and desferrioxamine against hepatotoxicity of carbon tetrachloride in mice. Life Sci. 2000;66: 2583-91. https://doi.org/10.1016/S0024-3205(00)00592-39.

37. Nili-Ahmadabadi A, Tavakoli F, Hasanzadeh G, Rahimi H, Sabzevari O. Protective effect of pretreatment with thymoquinone against Aflatoxin $B(1)$ induced liver toxicity in mice. Daru. 2011;19:282-7.

38. Al-Malki AL, Sayed AA. Thymoquinone attenuates cisplatin-induced hepatotoxicity via nuclear factor kappa-beta. BMC Complement Altern Med. 2014;14:282

39. Aycan IO, Tufek A, Tokgoz O, Evliyaoglu O, Firat U, Kavak GO, Turgut H, Yuksel MU. Thymoquinone treatment against acetaminophen-induced hepatotoxicity in rats. Int J Surg. 2014;12:213-8.

40. El-Sheikh AA, Morsy MA, Abdalla AM, Hamouda AH, Alhaider IA. Mechanisms of Thymoquinone Hepatorenal protection in methotrexateinduced toxicity in rats. Mediat Inflamm. 2015;2015:859383.

41. Farag MM, Ahmed GO, Shehata RR, Kazem AH. Thymoquinone improves the kidney and liver changes induced by chronic cyclosporine a treatment and acute renal ischaemia/reperfusion in rats. J Pharm Pharmacol. 2015;67:731-9.

42. Helal GK. Thymoquinone supplementation ameliorates acute endotoxemiainduced liver dysfunction in rats. Pak J Pharm Sci. 2010;23:131-7.

43. Awad AS, Abd Al Haleem EN, El-Bakly WM, Sherief MA. Thymoquinone alleviates nonalcoholic fatty liver disease in rats via suppression of oxidative stress, inflammation, apoptosis. Naunyn Schmiedebergs Arch Pharmacol. 2016;389:381-91.

44. Attia A, Ragheb A, Sylwestrowicz T, Shoker A. Attenuation of high cholesterol-induced oxidative stress in rabbit liver by thymoquinone. Eur J Gastroenterol Hepatol. 2010;22:826-34.

45. Mohany M, El-Feki M, Refaat I, Garraud O, Badr G. Thymoquinone ameliorates the immunological and histological changes induced by exposure to imidacloprid insecticide. J Toxicol Sci. 2012;37:1-11. https://doi.org/10.2131/jts.37.1.

46. Nagi MN, Alam K, Badary OA, Al-Shabanah OA, Al-Sawaf HA, Al-Bekairi AM. Thymoquinone protects against carbon tetrachloride hepatotoxicity in mice via an antioxidant mechanism. Biochem Mol Biol Int. 1999:47:153-9.

47. Abdel-Wahab WM. Thymoquinone attenuates toxicity and oxidative stress induced by bisphenol a in liver of male rats. Pak J Biol Sci. 2014;17:1152-60.

48. Alenzi FQ, El-Bolkiny YS, Salem ML. Protective effects of Nigella sativa oil and thymoquinone against toxicity induced by the anticancer drug cyclophosphamide. Br J Biomed Sci. 2010;67:20-8.

49. Suddek GM. Protective role of thymoquinone against liver damage induced by tamoxifen in female rats. Can J Physiol Pharmacol. 2014;92:640-4.

50. Aras S, Gerin F, Aydin B, Ustunsoy S, Sener U, Turan BC, Armutcu F. Effects of sodium arsenite on the some laboratory signs and therapeutic role of thymoquinone in the rats. Eur Rev Med Pharmacol Sci. 2015;19:658-63.

51. Abd-Elbaset M, Arafa EA, El Sherbiny GA, Abdel-Bakky MS, Elgendy AN. Thymoquinone mitigate ischemia-reperfusion-induced liver injury in rats: a pivotal role of nitric oxide signaling pathway. Naunyn Schmiedebergs Arch Pharmacol. 2017;390:69-76.

52. Nagi MN, Almakki HA, Sayed-Ahmed MM, Al-Bekairi AM. Thymoquinone supplementation reverses acetaminophen-induced oxidative stress,nitricoxide production and energy decline in mice liver. Food Chem Toxicol. 2010;48:2361-5.

53. Hassanein KM, EIAmir YO. Protective effects of thymoquinone and avenanthramidesontitaniumdioxide nanoparticles induced toxicity in Sprague-Dawley rats. Pathol Res Pract. 2017;213:13-22. 